\title{
Sobre a Possibilidade de Conciliação do Ideal da Integralidade nos Cuidados à Saúde e a Cacofonia da Demanda'
}

\section{On the Possibility of Conciliating the Ideal of Integral Health Care and the Cacophony of Health Demands'}

Mary Jane P. Spink

Doutora em Psicologia Social e Professora titular da Pontifícia Universidade Católica de São Paulo.

E-mail: mjspinkळpucsp.br

I Este artigo resulta de duas comunicações realizadas durante o $13^{\circ}$ Encontro Nacional da Associação Brasileira de Psicologia Social (ABRAPSO), Belo Horizonte, de 11 a 15 de novembro de 2005.

\section{Resumo}

O objetivo deste artigo é refletir sobre a factibilidade da aplicação plena dos princípios da integralidade nos serviços de atenção à saúde. Propomos que, para além do nível de abstração, quando analisado a partir da zona caótica das interações cotidianas, o princípio da integralidade é fractal: reflete visões de mundo coerentes em seus microcontextos, mas nem sempre passíveis de considerar as igualmente diversas visões de mundo dos interstícios interpessoais dessas redes de acolhimento e atendimento às demandas em saúde. Para entender essa dinâmica, foi realizado um exercício de análise discursiva, que procurou contrapor a diversidade semântica à variedade de posições de pessoa que se faz presente no cotidiano das práticas de saúde. Iniciamos pela caracterização do ideal da integralidade e suas relações com a demanda, pontuando a diversidade de seus sentidos e tomamos como exemplo documentos voltados à operacionalização do SUS. Em seguida, aprofundamos a reflexão sobre a diversidade semântica de demanda com base em seus significados dicionarizados, definindo, a partir deste exercício, tipos de posições de pessoa em relações dialógicas que envolvem demandas. Para isso, utilizamos uma experiência pessoal recente de internação hospitalar de uma paciente que nos levou a problematizar os dilemas éticos que se apresentam no cuidado a pacientes terminais.

Palavras-chave: Integralidade; Demanda; Práticas discursivas; Posições de pessoa; Serviços de saúde; Bioética. 


\section{Abstract}

The aim of this article is to reflect on the feasibility of applying the principle of integral care to health services in Brazil. We propose that as we leave the level of abstraction and enter the chaos of day-to-day interactions, the notion of integral care is fractal: it reflects world views that are coherent in their microcontexts, but are not always able to understand the diverse world views present in the interpersonal interactions of the network of care for health demands. In order to understand this complex interpersonal dynamics, an exercise in discursive analysis was carried out to contrast semantic diversity with the variety of person positions that are present in the daily life of health practices. We started by characterizing the ideal of integral care and its relation with health demands examining the diversity of meanings that are present in legislation concerning the Public Health System in Brazil. This analytic exercise was then followed by a dictionary investigation of the semantic diversity of the term demand so as to define a typology of person positions in dialogical interactions involving health demands. To illustrate this, we used a recent personal hospitalization experience of a patient that led us to reflect, also, on the ethical dilemmas that are present in the care of terminal patients.

Keywords: Integral Care; Health Demands; Discursive Practices; Person Positions; Health Services, Ethics.
As considerações que faremos neste artigo estão pautadas na defesa intransigente dos princípios do Sistema Único de Saúde (SUS) e na esperança de seu sucesso. Mas não é um texto ameno. Não serão repetidos os discursos idealizados de seus princípios e, no caso específico da problematização sobre demanda, do ideal da integralidade. No plano da abstração, o princípio da integralidade é incontestável. Sem qualquer dúvida, queixas, dores, mal-estares devem ser considerados "em contexto" e resolvidos na cooperação harmoniosa de profissões e especialidades profissionais diversas. Entretanto, observado a partir da zona caótica das interações cotidianas, o princípio da integralidade é fractal: reflete visões de mundo coerentes em seus microcontextos, mas nem sempre passíveis de considerar as igualmente diversas visões de mundo dos interstícios interpessoais dessas redes de acolhimento e atendimento às demandas em saúde.

É, portanto, no microcosmo das demandas que problematizaremos as realizações cotidianas do princípio da integralidade. Adotaremos uma perspectiva discursiva, acompanhando as teorizações que vêm sendo feitas no âmbito do Núcleo de Estudos e Pesquisas em Práticas Discursivas e Produção de Sentidos da Pontifícia Universidade Católica de São Paulo (Spink, 1999; 2004), que toma a linguagem em sua espiral de sentidos que as redes e suas articulações dialógicas colocam em movimento. A subjetividade, portanto, será aqui reinterpretada como co-construção de sentidos em relações dialógicas nas quais somos posicionados como sujeitos.

Iniciaremos pela caracterização do ideal da integralidade e suas relações com a demanda, pontuando a diversidade de seus sentidos; tomaremos como exemplo documentos voltados à operacionalização do SUS. Aprofundaremos a reflexão sobre a diversidade semântica de demanda com base em seus significados dicionarizados, definindo, a partir deste exercício, tipos de posições de pessoa em relações dialógicas que envolvem demandas. Para isso, utilizaremos uma experiência pessoal recente de internação hospitalar de uma paciente, que nos leva a problematizar os dilemas éticos que se apresentam no cuidado a pacientes terminais. 


\section{Da Relação entre Integralidade e Demanda}

É de conhecimento comum que o SUS tem por base três princípios: universalidade do atendimento, eqüidade e integralidade. A universalidade se aplica a todos igualmente: todos temos direito à saúde, que é um direito de cidadania e um dever do Estado.

A eqüidade, contudo, já postula a diferença. Todo cidadão é igual perante o SUS e será atendido segundo suas necessidades que, nesta formulação, são singulares e específicas a cada um. Entretanto, há um reconhecimento formal na legislação do SUS (Lei ${ }^{\circ}$ 8.o8o, de 1990) de que as necessidades não são apenas da ordem das individualidades. Tendo por base a epidemiologia, a gestão do SUS reconhece que, em cada população, existem grupos que vivem de forma diferente, ou seja, cada grupo, classe social ou região tem seus problemas específicos, decorrentes das diferenças no modo de viver, de adoecer e de ter oportunidades de satisfazer suas necessidades de vida. Reconhece, portanto, o imperativo de tratar desigualmente os desiguais, com implicações importantes para a questão da demanda.

A integralidade de assistência, segundo o texto legal (Brasil, Lei no 8080/9o), é entendida como o conjunto articulado e contínuo de ações e serviços preventivos e curativos, individuais e coletivos, exigidos para cada caso, em todos os níveis de complexidade do sistema. Mesclam-se, aí, ações de promoção, proteção e recuperação de agravos à saúde que, diante da complexidade que se faz presente, exige a ação de pessoas com diferentes especialidades e capacitações. A integralidade, portanto, é de ordem da multidisciplinaridade e envolve múltiplas especialidades que se entrecruzam para dar resposta a demandas e necessidades; começamos, assim, a penetrar um curioso imbróglio discursivo.

Para ilustrar essa cacofonia discursiva, utilizaremos como exemplo o texto da Norma Operacional Básica do Sistema Único de Saúde, conhecido como NOBSUS o1/96, publicada no Diário Oficial da União, em 6 de novembro de 1996. A NOB96 faz referência à demanda em três capítulos: o da finalidade, o dos campos de atenção à saúde e o da relação entre os sistemas municipais.

\section{O capítulo intitulado "Finalidade" afirma:}

A presente Norma Operacional Básica tem por finalidade primordial promover e consolidar o pleno exercício (...) da função de gestor da atenção à saúde dos seus munícipes (...) avançando na consolidação dos princípios do SUS. Esse exercício, viabilizado com a imprescindivel cooperação técnica e financeira dos poderes públicos estadual e federal, compreende, portanto, não só a responsabilidade por algum tipo de prestação de serviços de saúde (Artigo 3o, inciso VII), como, da mesma forma, a responsabilidade pela gestão de um sistema que atenda, com integralidade, à demanda das pessoas pela assistência à saúde e às exigências sanitárias ambientais (Artigo zo, inciso V). Busca-se, dessa forma, a plena responsabilidade do poder público municipal. (...) Isso implica aperfeiçoar a gestão dos serviços de saúde no país e a própria organização do Sistema, visto que o município passa a ser, de fato, o responsável imediato pelo atendimento das necessidades e demandas de saúde do seu povo e das exigências de intervenções saneadoras em seu território." (ênfases nossas).

\section{O capítulo "Campos da atenção à saúde" informa que:}

A atenção à saúde, que encerra todo o conjunto de ações levadas a efeito pelo SUS, em todos os níveis de governo, para o atendimento das demandas pessoais e das exigências ambientais, compreende três grandes campos, a saber: a) o da assistência (...); b) o das intervenções ambientais (...); e (c) o das políticas externas ao setor saúde (...).

\section{No capítulo sobre "Relações entre os sistemas municipais" afirma-se que:}

os recursos destinados ao pagamento das diversas ações de atenção à saúde prestadas entre municípios são alocados, previamente, pelo gestor que demanda esses serviços, ao município sede do prestador. Este município incorpora os recursos ao seu teto financeiro. A orçamentação é feita com base na programação pactuada e integrada entre gestores, que, conforme já referido, é mediada pelo estado e aprovada na CIB regional e estadual e no respectivo Conselho de Saúde.

Há aqui um deslizamento semântico que nos leva da demanda como necessidade de atenção por parte de pessoas para a ação de demandar, com o sentido 
de pedir. É justamente esse deslizamento o foco de nossas considerações. Poderíamos ter escolhido outros documentos, como as Normas Operacionais de Assistência à Saúde - NOAS ou a Programação Pactuada e Integrada (PPI) da assistência, mas nossa intenção não é fazer uma análise discursiva da polissemia presente nesses documentos, é propiciar a reflexão sobre as possibilidades (ou impossibilidades) de negociar os sentidos de demanda no cotidiano das práticas de atenção à saúde, pois, como afirmam Pinheiros e Mattos:

A construção social da demanda se apresenta como fio da meada de um percurso analítico de redes constituintes de práticas de integralidade, nas quais o diálogo entre os processos históricos e a experiência vivida tem origem no movimento da reforma sanitária brasileira. Demanda que se constrói na luta pela garantia do direito à saúde como questão de cidadania, na conformação de um trabalho em equipe com profissionais qualificados capazes de reconhecer a alteridade dos usuários e a participação dos sujeitos com suas diferentes vozes ecoadas em distintos espaços públicos. (2005, p. 6)

Como no exemplo da NOB-SUS o1/96, temos partícipes diversos nesse processo de atendimento à de- manda: a) gestores que demandam serviços, mas têm de programar ações que visem regular oferta e demanda desses serviços; b) membros da equipe profissional que podem compartilhar uma definição de demanda, mas que a abordam com base em suas posições de poder no sistema e c) pessoas que buscam atendimento por necessidades, que podem ser ou não compatíveis com os critérios da gestão.

O exercício de análise discursiva a que nos propomos visa contrapor a diversidade semântica à variedade de posições de pessoa, presente no cotidiano das práticas de saúde.

\section{A Diversidade Semântica na Perspectiva dos Significados Dicionarizados}

Como passo inicial desse exercício de análise discursiva, verificamos as acepções de demanda nos dicionários Aurélio e Houaiss e encontramos 12 diferentes. Como não se trata de escolher a melhor, somamos as definições por categoria de sentido e criamos a Figura 1 que compara o substantivo demanda e o verbo demandar.

\section{Figura I - Os múltiplos sentidos de demanda}
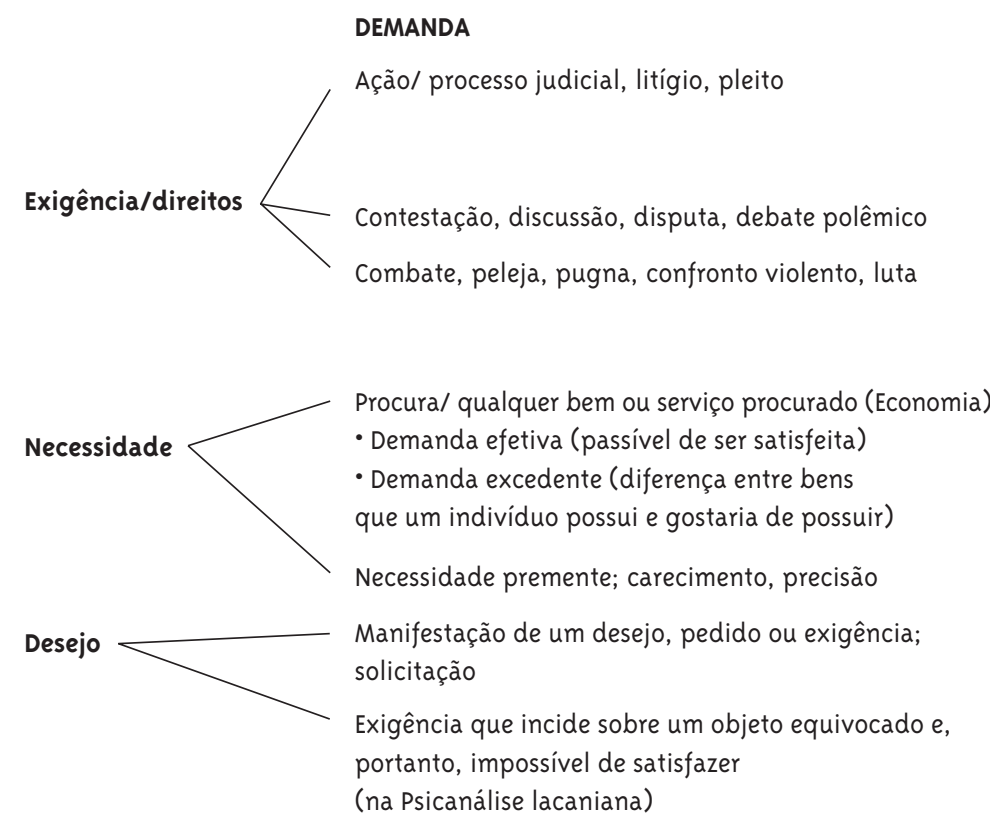

\section{DEMANDAR}

Intentar ação judicial, ou demanda, contra; processar, acionar; instaurar processo judicial contra pessoa ou instituição

Disputar, contender, litigar

Reclamar, pedir, exigir, requerer judicialmente; tentar obter, através de pedido ou exigência, requerer reivindicar

Ter/apresentar necessidade de, precisar de, necessitar

Ir/partir em busca de, procurar

Pedir, solicitar 


\section{As acepções de demanda}

(a) Como direito, remetendo ao campo jurídico que se configura como cenário de litígio e contestação quando as demandas-direitos não são atendidas.

(b) Como necessidade, que remete ao campo da economia e ao discurso de oferta e demanda.

(c) Como precisão e carência, necessidades que, no caso de estados democráticos pautados pela lógica dos direitos de cidadania, são de competências do Estado. Nesse caso, a definição da carência é também de competência definindo as prioridades com base na epidemiologia.

(d) Como desejo, que concerne à esfera da subjetividade, das necessidades sentidas, que são levadas aos atendimentos de saúde como problemas a serem resolvidos.

Considerando a etimologia, constatamos que Demanda é um termo formado por derivação regressiva do verbo demandar, que vem do latim: mandáre. Voltando às raízes, encontramos diversos significados de mandar, os quais reorganizamos, na Figura 2, nas suas duas principais acepções: confiar e mandar.

\section{Figura 2 - Os diversos sentidos de "mandar"}
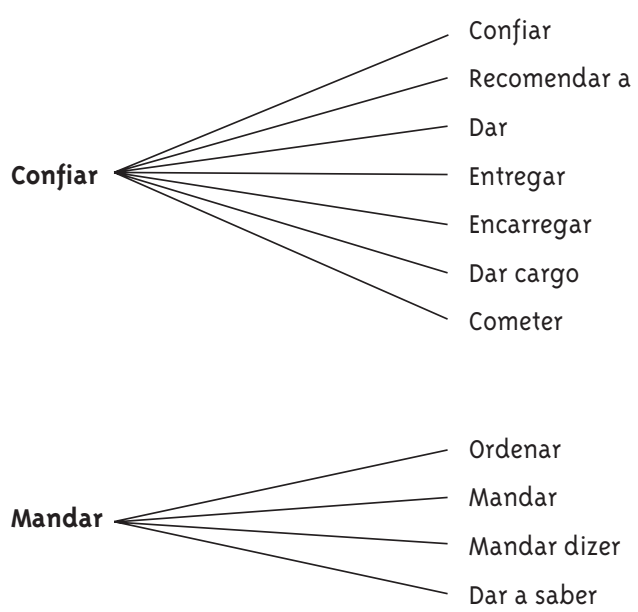

\section{Os diversos sentidos de mandar}

Além disso, percebemos que demanda é um termo composto por uma preposição e por um substantivo ou verbo. Continuaremos o exercício, buscando entender as implicações da preposição "de" que pode assumir os seguintes sentidos:

- de cima de, sobre, no alto de;

- de fora de, procedente de;

- em, do meio de;

- debaixo de, depois de;

- à custa de, feito de, por causa de, acerca de;

- em vez de, contra.

A preposição de, por sua vez, ocorre em um número significativo de vocábulos, formados a partir do latim e geram as noções de:

- movimento de cima para baixo, descida: decurso, defluxo, dejeção, devolver;

- afastamento, separação, repulsa: demover, deprecação, derivar, detestar;

- diminuição, redução: decapitar, decrescer, dedução, deduzir;

• privação, negação: decompor, deforme, delir, demente; - acabamento, consumação: debelar, depauperar, determinar;

- intensidade: dearticular, dessudação, detonar;

• progressão, continuação: decair, deperecer;

\section{Demandas, Direitos de Usuários e Omissão de Socorro: dilemas éticos no cuidado de pacientes terminais}

Com base nesta diversidade, buscamos contrapor preposições, movimentos e significados de demanda, pensando nas interações resultantes de distintas posições de pessoa, ocupadas por médicos, gestores, usuários de serviços, familiares/acompanhantes, e seus efeitos na perspectiva de tornar possível a integralidade no atendimento à saúde. Usamos, como estudo de caso, uma experiência recente de internação de uma pessoa, por meio de plano de saúde. Trata-se de internação em hospital particular e de atenção especializada. Partimos do pressuposto de que as posições de pessoa aqui identificadas traduzem posturas ainda 
hegemônicas na maioria dos serviços de saúde - públicos ou privados -, que teriam de ser ressignificadas para que pudéssemos entrar plenamente na era da integralidade na atenção em saúde.

Este é o caso de uma senhora de 93 anos, internada com um quadro de úlceras de pressão gangrenadas e infecção pulmonar. A paciente apresentava problemas circulatórios e diabetes, era lúcida, alegre, e, até recentemente, autônoma nos afazeres cotidianos. Foi internada por recomendação de sua médica geriatra, a qual considerou que o tratamento das feridas exigia cuidado profissional.

O processo de negociação de sentidos envolveu diversos personagens. Em primeiro lugar, a paciente, que traz uma demanda que se concretiza em três dimensões: dos direitos, pois paga um plano de saúde que lhe dá certos direitos (mas que no SUS são intrínsecos ao texto constitucional, pois saúde é um direito de todos); das necessidades, entendidas nesta posição de pessoa como carência de cuidados especializados; e dos desejos, que, neste caso específico, se caracterizam como impossibilidade de recuperação plena da saúde e da autonomia em quadro de doença crônica. Trata-se de posição debaixo de, com pouco poder de barganha, gerando movimentos de diminuição, privação e progressão_negativa.

Introduziremos nessa equação comunicativa a médica geriatra, que a internou, por diagnosticar a gravidade do quadro e pela impossibilidade de tratá-lo em casa com a competência técnica necessária. A médica é ator coadjuvante, pois, como não faz parte do corpo clínico do hospital, fala de fora do sistema, mas pleiteia, em um complicado processo de negociação, ser ouvida como médica da família e, portanto, como do meio de. Alia-se à paciente e à família na perspectiva da demanda que nos fala de direitos: de não ter dor, de estabilizar o quadro e retornar a casa e, até mesmo, de reassumir seus hábitos domésticos cotidianos.

A família assume posição semelhante à da médica e situa-se, em termos de demanda, no enquadre dos direitos. No processo de negociação, a família, por meio de sua porta-voz, brigou para sair da posição debaixo de e falar do meio de, pleiteando uma competência técnica de outra ordem, baseada na informação que resulta em um movimento de acabamento/ consumação: a conquista do direito de não-realização de procedimentos intensivos - que levariam à internação na UTI - e o direito a home care.

A posição médica se faz presente na voz do médico clínico responsável pelo caso, que assume a posição de cima de: define procedimentos, dá o aval. Falando de cima para baixo, interpreta demanda como necessidade no sentido estreito de corpo biológico e gera um movimento de afastamento, separação, em relação à família e à geriatra. Trata a paciente com o respeito devido, mas com o movimento de diminuição e redução, que impede qualquer possibilidade de autonomia. Sua voz ecoa na dos especialistas diversos, da área médica, da fonoaudiologia, da fisioterapia, que estão lá como coadjuvantes da ação terapêutica por terem sido chamados pelo médico responsável, coadjuvantes da ação terapêutica. A demanda, no caso, não é só a do paciente. Como os gestores na citação da NOB-SUS o1/96, respondem, sobretudo, à demanda do médico responsável. 0 movimento é de progressão, continuação, e por meio dele sempre temos a impressão de que o caso está melhorando.

Finalmente, temos os gestores, representados no exemplo pelos responsáveis pelo caso, na perspectiva do plano de saúde (mas que, no SUS, adotariam a ótica das NOAS). Entramos no terreno dos direitos, das necessidades e dos desejos, reinterpretados à luz do que o plano específico permite ou não. Estamos no enquadre de cima para baixo, no que diz respeito à paciente, mas de fora de no que se refere à conduta clínica. É uma arena de contestação e disputa entre o corpo clínico do hospital e as normas operacionais (do plano de saúde ou do SUS), entre familiares e plano de saúde (ou SUS).

\section{Negociando Sentidos de Demandas e Procedimentos no Cotidiano das Práticas de Saúde}

A internação, em ocorrências como essa, se dá pelo Pronto Socorro (PS) - ou por ter sido feita no final da tarde de uma sexta-feira, ou por ser procedimento próprio de PS -, a responsabilidade pelo caso ficou nas mãos de um médico da equipe da Unidade Intensiva do hospital.

Os primeiros dias foram confusos. Era fim de semana, quando os hospitais funcionam com plantonistas que não dão informações ou mudam procedimen- 
tos. A médica da família, que não era credenciada pelo hospital, estava fora da cidade e só pôde fazer uma visita na segunda-feira. Diante da gravidade do quadro das feridas, falava-se recorrentemente em amputação. Amputação em uma senhora de 93 anos? - indagávamos. Seríamos consultados? Assinaríamos um termo de consentimento? Poderíamos impedir esse procedimento? Poderíamos negociar a volta a casa, em home care, e evitar, pelo menos, a internação em UTI?

Foram essas questões e a vivência tensa das negociações de tratamento de pacientes vulnerabilizados pelo estado precário da saúde no contexto hospitalar que nos desafiaram a buscar entender os complexos processos de negociação na contraposição entre direitos do paciente, deveres do médico e limites impostos pelo plano (ou sistema) de saúde. Ética, deontologia e crime de omissão de socorro passaram a ser as palavras-chave nesse intenso processo de negociação, que envolveu médicos, com visões de mundo muito distintas, a família e, como pano de fundo nebuloso, a paciente. Nebuloso porque, à medida que as terapias iam se avolumando e interagindo, sua capacidade para opinar e exercer autonomia tornaram-se cada vez mais tênues.

\section{O Plano da Ética: sobre o juramento de Hipócrates e "futilidades terapêuticas"}

A despeito das imensas transformações tecnológicas e sociais, persiste ainda a visão hipocrática de boa prática médica. Esse é o campo da deontologia médica - a ciência que cuida dos deveres associados à prática profissional. 0 ideário hipocrático persiste no imaginário e nas práticas ritualísticas, como as cerimônias de colação de grau, que dão ao jovem estudante egresso de cursos de Medicina o título de "médico" com o direito imediato de praticar como tal.

Diz Rezende (2003, s/p): "O juramento de Hipócrates é uma obra de arte e sabedoria, só comparável às mais altas criações do espírito humano e, por isso mesmo, deve ser considerado patrimônio da humanidade e permanecer intocável, como um marco da história da medicina”. Dos 72 livros que compõem o Corpus hippocraticum, sete tratam exclusivamente da ética médica e, dentre eles, sobressai-se o Juramento, texto que enfatiza dois aspectos da prática médica que constituem, até hoje, seus alicerces: o sigilo e a beneficência.

Persiste o juramento a despeito das reformulações dos códigos profissionais da medicina que adaptam os imperativos morais da prática médica aos tempos atuais. Afinal, muitos dos preceitos hipocráticos, como a confidencialidade absoluta, a relação individualizada com o paciente (que se contrapõe aos preceitos da medicina social), a proibição da cirurgia e da experimentação, tornaram-se obsoletos.

No caminho da atualização ou da modernização do juramento hipocrático, foram feitas várias sugestões de modificação do texto, dentre as quais a principal foi a aprovada na Assembléia Médica Mundial, realizada em 1948, conhecida como Declaração de Genebra. Esse texto foi modificado ligeiramente em 1994, mas, com as adaptações necessárias, mantém o espírito hipocrático.

No caminho inverso, de reformulação substantiva em resposta às novas circunstâncias da prática médica pautada pela crescente especialização e institucionalização das ações, conforme o comentário de Neves (2005), a primeira formulação moderna do código de ética médica foi elaborada por Thomas Percival e publicada em 1803. Seu livro, Medical Ethics: a code of institutes and precepts adapted to the professional conduct of physicians and surgeons, teve significativa influência nos códigos de ética profissional da GrãBretanha e dos Estados Unidos (e, indiretamente, no de outros países). Seu código refletia o "novo espírito" que começava a embasar a Medicina e que, na visão de Neves, incluía os seguintes elementos: a cientificação do saber, com conseqüente aumento do poder dos médicos sobre os pacientes, seja pelo conhecimento que adquirem e que gera assimetria entre os dois seja pelo recurso a terapêuticas mais invasivas; a profissionalização e progressiva especialização dos praticantes e a institucionalização, que amplia a tradicional relação a dois para uma dinâmica triangular na qual a dimensão social se torna irrecusável.

Trata-se, porém, de um código de transição que mantém traços da ética hipocrática, mas não prevê alguns desdobramentos, que serão marcas da segunda metade do século XX. Como elos com o passado, mantêm-se, no código de Percival, duas características do juramento hipocrático: a beneficência como principal eixo da prática médica e o caráter virtuoso 
do médico, como sustentação da boa prática clínica. Antecipando a profissionalização moderna da medicina, trata da relação entre especialidades e da institucionalização da prática, mas não antecipa o que vem a ser característica principal dos modernos códigos: a questão dos direitos do paciente.

\section{Interlúdio para Falar de Bioética}

Os desdobramentos da bioética na segunda metade do século XX é que vão dar novas conotações aos direitos do paciente, pautadas, sobretudo, pela reação às atrocidades cometidas pelos nazistas durante a Segunda Guerra Mundial, assim como pelo debate suscitado pelas experiências com terapêuticas variadas em populações vulneráveis (Menegon, 2006). Segundo Kovács (2003), a breve história da bioética compreende três fases: a primeira, centrada na discussão dos valores humanos, tem a teologia como principal interlocutor; a segunda, tem a filosofia com paulatina ampliação para um olhar multidisciplinar envolvendo as ciências humanas, o direito e a psicologia, entre outros campos de saber; a terceira fase, ainda seguindo o raciocínio de Kovács, "começam a ter lugar as discussões envolvendo a macropolítica da saúde, a economia e a questão dos excluídos" (2006, p.118).

Neste contexto se cristalizaram os três princípios que regem a bioética: autonomia, beneficência e justiça. A autonomia refere-se ao respeito, à vontade, do paciente e ao direito de autogovernar-se. A beneficência pauta-se pelo princípio de fazer o bem e evitar o sofrimento adicional. 0 princípio da justiça relaciona-se à liberdade contratual e à eqüidade.

Dos três princípios, é a autonomia e a beneficência que parecem estar em maior tensão, especialmente se vistos sob a ótica do desenvolvimento da tecnologia médica, que possibilita estender a sobrevida por meio de tubos e máquinas. Entramos aqui no campo da distanásia, a "morte defeituosa" (em oposição à eutanásia: a boa morte). Segundo Kovács:

A distanásia é sempre o resultado de uma determinada ação ou intervenção médica que, ao negar a dimensão da mortalidade humana, acaba absolutizando a dimensão biológica do ser humano. (2003, p.153)

Levando-se isso em consideração, deparamo-nos com dois conceitos que têm sentidos para a clínica médica, mas nem sempre o têm para quem vivencia, como paciente ou familiar, o processo de distanásia: a obstinação terapêutica e a futilidade terapêutica.

A obstinação terapêutica é definida "como utilização de meios desproporcionais no tratamento dos pacientes e que conduz, muitas vezes, a situações inaceitáveis sob o ponto de vista clínico e ético" (Urban e col., 2001, p.245). Os tratamentos fúteis são "aqueles que não conseguem manter ou restaurar a vida, garantir o bem-estar, trazer à consciência, aliviar o sofrimento; ao contrário, só levam a sofrimentos adicionais" (Kovács, 2003, p.154).

Apresenta-se aqui a difícil questão de definir o que é um tratamento desproporcional; de estabelecer, para cada caso, o que é ético e cientificamente adequado e, portanto, pautado pelo princípio da beneficência; e o que é desproporcional, acarretando mais sofrimento e ferindo o princípio da não-maleficência. Amputar a perna de uma paciente idosa com quadro de arteriopatia, por exemplo, ou interná-la na UTI para dar-lhe "melhor suporte" - técnico, é claro?

É a partir da ameaça de duas condutas inteiramente justificáveis do ponto de vista clínico, mas contrárias ao princípio de humanização da morte, que fomos em busca de subsídios para entender quais são, de fato, os direitos do paciente.

\section{O Paciente e sua Família: os direitos com o apoio da lei}

Em março de 1999, no governo de Mário Covas, foi aprovada a Lei Estadual $n^{0} 10.241$, de autoria do Deputado Roberto Gouveia que "Dispõe sobre os direitos dos usuários dos serviços e das ações de saúde no Estado e dá outras providências". Dos cinco artigos originais, apenas dois foram referendados, sendo o segundo o tema-foco da lei, dispondo, nos 22 incisos aprovados, uma listagem compreensiva dos direitos dos usuários de serviços de saúde.

A lei foi reproduzida na íntegra em artigo de Oselka, publicado na Revista da Associação Médica Brasileira, RAMB, em 2001, "não só para conhecimento dos médicos paulistas, mas principalmente para estimular discussões e ações que levem à adoção de leis semelhantes em outros Estados e em nível federal" (2001, p. 105). Sendo Oselka profundo conhecedor das querelas éticas relacionadas ao exercício profissional, a divulgação tardia, dois anos após a pro- 
mulgação da lei, sugere que a ela teve pouco impacto na discussão vigente sobre exercício profissional, resquício, talvez, da hegemonia da visão hipocrática que, a despeito da perspectiva holística de saúde e dos ensinamentos a ela associados, posiciona pacientes em uma relação assimétrica com os médicos. Tratase de atitude pouco compatível com a recentíssima perspectiva dos direitos, que procura estabelecer a simetria na relação médico-paciente (Castiel e Vasconcellos-Silva, 2006).

Neste artigo, Oselka destaca dois tópicos: o inciso XXIII - que estabelece a possibilidade de recusa de tratamentos dolorosos ou extraordinários para prolongar a vida, e o XXIV, sobre o direito do paciente de optar pelo local da morte. Conforme Oselka, com estes direitos estabelecidos em lei, "oferece-se respaldo legal aos médicos que acreditam que em alguns pacientes terminais, e com a concordância dos mesmos ou de quem responda por eles, a não introdução ou a interrupção de medidas para prolongamento da vida é a conduta ética a ser adotada” (2001, p.105).

Mas Ozelka e outros especialistas reconhecem que a questão é "espinhosa”. De um lado, como aponta Kovács (2003), pedidos explícitos para morrer não são fáceis de avaliar e podem ter conotações muito distintas, relacionados, por exemplo, à solidão, à depressão ou podem ser utilizados como estratégia para conseguir atenção (há uma literatura rica a esse respeito, proveniente de países onde as ordens para não ressuscitar são reconhecidas legalmente - Urban e col., 2001), de outro, o princípio da beneficência impõe que seja prestada assistência, sendo a definição de assistência igualmente complexa. Ninguém contesta que os cuidados básicos sejam mantidos. Mas o que vem a ser "básico"? Uma sonda naso-gástrica para alimentação parenteral ou uma entubação?

É nesse contexto que a discussão deixa o espaço mais restrito das práticas médicas e amplia-se de modo a considerar os aspectos econômicos da prestação de cuidados à saúde - seja no contexto do SUS seja no dos planos de saúde privados - e o emaranhado legal das possíveis acusações de omissão de socorro. Este é, de fato, o "nó" da questão. Por mais que pacientes e familiares concordem ou exijam que não sejam feitos tratamentos extraordinários para prolongar a vida, nosso Código Penal, que data de 1940, não contempla questões próprias da era dos direitos. Reza o artigo 135 do Código Penal que "Deixar de prestar assistência, quando possível fazê-lo sem risco pessoal, à criança abandonada ou extraviada, ou à pessoa inválida ou ferida, ao desamparo, ou em grave e iminente perigo; ou não pedir nestes casos o socorro da autoridade pública" é crime de omissão de socorro.

Acrescente-se ao problema o fato de que direitos são inalienáveis; dar ordens de não ressuscitar ou expressar desejo de que não sejam feitos procedimentos fúteis não têm, no Brasil, respaldo legal.

Como se orientar neste imbróglio de normas, regulamentos, leis e limites estabelecidos pelo sistema de saúde que está sendo utilizado? No caso aqui relatado, a família procurou sair da posição de fora de e assumir mais poder no processo de negociação usando como estratégias: a) a divulgação ampla de familiaridade com a legislação; b) a formação de alianças com a médica da família que, sendo geriatra, estava familiarizada com os princípios da medicina paliativa e era totalmente a favor de levar a paciente de volta para casa, em home care; c) a abertura de espaços de diálogo com o clínico responsável pelo caso, buscando informações diagnósticas e questionando, a cada passo, a necessidade de certas intervenções, sobretudo da necessidade de internação em UTI; d) a inclusão, nesse processo dialógico, dos gestores do plano de saúde, deixando clara a intenção da família de cuidar da paciente em casa; e e) a explicitação, em todos os momentos possíveis, da necessidade de pensar na dignidade da morte, na qualidade da morte e não apenas na qualidade da vida.

Foi um processo lento de negociação que se fez à margem da lei dos direitos do paciente: a informação dada nem sempre era completa (a não ser quando mediada pela médica da família); o acesso ao prontuário, embora não tenha sido negado, não foi facilitado; nenhum dos procedimentos realizados - diagnósticos ou terapêuticos - foi acompanhado de consentimento, esclarecido ou não. À medida que se confirmava a gravidade do quadro circulatório e, conseqüentemente, a reclassificação da amputação como "tratamento fútil" e diante da objeção da família às medidas intervencionistas que redundariam em internação em UTI, foi se configurando como solução o cuidado domiciliar. E o desfecho se deu desta forma. Não foi fácil: há ciladas múltiplas no fornecimento de home care. Mas isso é uma outra história que fica para uma outra vez. 


\section{Concluindo}

Concordamos com Kovács quando ele afirma que "a humanização da morte não é o seu apressamento, nem seu prolongamento indefinido" (2003, p.158) Consideramos, ainda, que a dignidade é um valor fundamental, mais do que a autonomia ou a autodeterminação, pois estas nem sempre podem se fazer presentes nesse momento.

Se a pessoa que constituiu nosso estudo de caso tivesse autonomia, seu desejo seria não ser internada: "Doutora, a senhora não vai fazer isso comigo!" foram suas palavras diante da argumentação da médica sobre a necessidade de cuidar das feridas em hospital. Podíamos e procuramos atender o quesito dignidade, possibilitando que a paciente passasse seus últimos dias em companhia da família e de amigos, cuidada em suas necessidades básicas, físicas, psicológicas e espirituais.

Em suma, o que buscamos fazer neste artigo foi situar a integralidade na perspectiva da subjetividade, tomando-a como processo de negociação de sentidos da demanda. Em uma perspectiva discursiva, a demanda é uma mescla de direitos, necessidades e desejos, que assumem conotações distintas, de acordo com o processo específico de interanimação dialógica. Essas trocas discursivas, que mesclam socialidades e materialidades, ocorrem em contextos definidos pelas posições de pessoas que se fazem presentes.

Estas reflexões não dão conta dos problemas com os quais o nosso Sistema Único de Saúde se depara, na consolidação de seus ideais. Nossa contribuição singela será, talvez, chamar a atenção para a necessidade de se precaver a adoção de discursos simplistas e impossíveis de serem traduzidos em ação.

\section{Referências}

BRASIL - Lei n 8.080 , de 19 de setembro de 1990. Dispõe sobre as condições para a promoção, proteção e recuperação da saúde, a organização e o funcionamento dos serviços correspondentes e dá outras providências. Diário Oficial da União, Brasília, DF, 9 set. 199o, p.18.055

BRASIL. Norma Operacional Básica do Sistema Único de Saúde/NOB-SUS 96. Diário Oficial da União, Brasília, DF, 1997. 34 p.

CASTIEL, L. D.; VASCONCELLOS-SIVA, P. R. Precariedades do excesso: informação $e$ comunicação em saúde coletiva. Rio de Janeiro: Fiocruz, 2006. 168 p.

FERREIRA, A. B. de H. Novo dicionário Aurélio da Língua portuguesa. Curitiba (PR): Editora Positivolivros, 2004. $2120 \mathrm{p}$.

HOUAISS, A \& Villar, M. de S. Dicionário Houaiss da Língua Portuguesa. Rio de Janeiro: Objetiva, 2001. $2922 \mathrm{p}$.

KOVÁCS, M. J. Bioética nas questões da vida e da morte. Psicologia USP, São Paulo, v. 14, n. 2, p. 115$167,2003$.

MENEGON, V. S. M. Entre a linguagem dos direitos e a linguagem dos riscos: os consentimentos informados na reprodução humana assistida. São Paulo: Educ/Fapesp, 2006.

NEVES, M. P. Thomas Percival: tradição e inovação. Bioética, São Paulo, v. 11, n. 11, p. 11-22, 2003.

OSELKA, G. Direitos dos pacientes e legislação. Revista da Associação Médica Brasileira, São Paulo, v. 47, n. 2, p. 85-109, 2001.

PINHEIROS, R. \& MATTOS, R. A Construção social da demanda. Rio de Janeiro: CEPESC, 2005.

REZENDE, J. M de. Caminhos da medicina. Revista Paraense de Medicina, Belém, Pará, v. 17, n. 1, p.3847, 2003. Disponível em: <http://usuarios.cultura. com.br/jmrezende> Acesso em 23 jul. 2006.

SÃO PAULO (Estado). Lei n ${ }^{\circ}$ 10.241, de 17 de março de 1999. Dispõe sobre os direitos dos usuários dos serviços e das ações de saúde no Estado e dá outras providências. Diário Oficial do Estado, São Paulo, SP, 18 mar. Seção 1, p.1.

SPINK, M. J. P. (org.). Práticas Discursivas e Produção de Sentidos no Cotidiano: aproximações teórico e metodológicas. São Paulo: Cortez, 1999.

SPINK, M. J. P. Linguagem e Produção de Sentidos no Cotidiano. Porto Alegre, EDIPUCRS, 2004.

URBAN, C. de A.; et al. Implicações éticas das ordens de não ressuscitar. Revista da Associação Médica Brasileira, São Paulo, v. 47, n. 3, p. 244-248, 2001.

Recebido em: 01/08/06

Aprovado em: 19/12/06 